\title{
Correction to: decision-making at the limit of viability: differing perceptions and opinions between neonatal physicians and nurses
}

Hans Ulrich Bucher ${ }^{1 *}$, Sabine D. Klein ${ }^{1}$, Manya J. Hendriks ${ }^{1,2}$, Ruth Baumann-Hölzle ${ }^{3}$, Thomas M. Berger ${ }^{4}$, Jürg C. Streuli ${ }^{2}$, Jean-Claude Fauchère ${ }^{1}$ and on behalf of the Swiss Neonatal End-of-Life Study Group

\section{Correction}

After publication of the original article [1], the corresponding author noticed the given names and family names of the members included in the Swiss Neonatal End-of-Life Study Group were incorrectly reverted. The correct version of the Acknowledgements section has been included in this Correction and includes the correct presentation of names for the members included in the Swiss Neonatal End-of-Life Study Group.
Published online: 09 July 2018

\section{Reference}

1. Bucher HU, et al. Decision-making at the limit of viability: differing perceptions and opinions between neonatal physicians and nurses. BMC Pediatr. 2018;18:81. https://doi.org/10.1186/s12887-018-1040-z.

\begin{abstract}
Acknowledgements
The Swiss Neonatal End-of-Life Study Group includes the following local coordinators (listed in alphabetical order of study site): Aarau: Neonatal Unit, Dept. of Paediatrics, Kantonsspital Aarau (Philipp Meyer, MD) - Basel: Neonatal Unit, University Children's Hospital Basel UKBB (Roland Neumann, MD; Renate Itin) - Bern: Neonatal Unit, University Children's Hospital, Inselspital (Mathias Nelle, MD; Liliane Stoffel) - Chur: Neonatal Unit, Dept. of Paediatrics, Kantonsspital Chur (Brigitte Scharrer, MD; Kai Roloff) - Geneva: Neonatology and Pediatric Intensive Care, Dept. of Paediatrics, University Hospital HCUG (Riccardo Pfister, MD) Lausanne: Division of Neonatology, Dept. of Paediatrics, University Hospital CHUV (Matthias Roth-Kleiner, MD; Magali Contino) - Lucerne: Neonatal Unit, Children's Hospital, Kantonsspital Luzern (Thomas M. Berger, MD; Ulrike Schlegel) St. Gallen: Neonatal Unit, Children's Hospital, Kantonsspital St. Gallen (Gudrun Jaeger, MD; Ruth Dutler) - Zurich: Department of Neonatology, University Hospital Zurich (Jean-Claude Fauchère, MD; Barbara Dinten).
\end{abstract}

\section{Author details}

'Department of Neonatology, University Hospital Zurich, Frauenklinikstrasse 10, 8091 Zürich, Switzerland. ${ }^{2}$ Institute of Biomedical Ethics and History of Medicine, University of Zurich, Zurich, Switzerland. ${ }^{3}$ Dialogue Ethics Foundation, Interdisciplinary Institute for Ethics in Health Care, Zurich, Switzerland. ${ }^{4}$ Neonatal and Paediatric Intensive Care Unit, Children's Hospital of Lucerne, Lucerne, Switzerland.

\footnotetext{
* Correspondence: buh@usz.ch

${ }^{1}$ Department of Neonatology, University Hospital Zurich, Frauenklinikstrasse 10, 8091 Zürich, Switzerland
}

( ) The Author(s). 2018 Open Access This article is distributed under the terms of the Creative Commons Attribution 4.0 International License (http://creativecommons.org/licenses/by/4.0/), which permits unrestricted use, distribution, and reproduction in any medium, provided you give appropriate credit to the original author(s) and the source, provide a link to the Creative Commons license, and indicate if changes were made. The Creative Commons Public Domain Dedication waiver (http://creativecommons.org/publicdomain/zero/1.0/) applies to the data made available in this article, unless otherwise stated. 